\title{
Analysis of Transient Voltage Stability for Wind Power Integrated System Based on DVR and Crowbar
}

\author{
Xiaoying Zhang ${ }^{1, \text { a }}$, Youzhen Liang ${ }^{1, b}$ and Kun Wang ${ }^{1, c}$ \\ ${ }^{1}$ College of Electrical and information Engineering, Lanzhou University of technology, Lanzhou \\ a245659219@qq.com, bliangyz1212@163.com, c471943808@qq.com
}

\begin{abstract}
Keywords: doubly-fed induction generator (DFIG); transient voltage stability; dynamic voltage restorer (DVR); rotor crowbar; coordinate control

Abstract: Aiming at the problems of transient voltage stability decreases, which caused by the doubly-fed wind power integrated system when grid short-circuit faults, a coordinated control strategy is proposed. This control strategy combines dynamic voltage restorer (DVR) based on the improved voltage drop detection algorithm and compensation method with rotor crowbar circuit. A simulation model is established in MATLAB/Simulink. The validity of the proposed coordinate control strategy in improving the transient voltage stability of doubly-fed wind power integrated system is verified by the simulation results.
\end{abstract}

\section{Introduction}

Among the wind turbine concepts, turbines using the doubly-fed induction generator (DFIG) are dominant as described in [1] due to the advantages of variable speed based operation and decoupled control of active and reactive power. While, with the stator of DFIG directly connected to the grid, it is very sensitive to grid disturbances [2].

To protect the rotor side power electronic converter under symmetrical and asymmetrical voltage dips, a resistive network called crowbar is connected in case of rotor over-currents or dc-link over-voltages to the rotor circuit [3,4]. But the machine draws a high short circuit current when the crowbar is activated, resulting in a large amount of reactive power drawn from the power network. Thus, other protection methods have to be investigated to guarantee reactive power. A system is introduced and is called dynamic voltage restorer (DVR) that is a voltage source converter connected in series to the grid to correct faulty line voltages. Simulation results in [5] show the effectiveness of the DVR in comparison to the low-voltage ride through (LVRT) of the DFIG using a Crowbar that does not allow continuous reactive power production. A coordinated control strategy, which uses super capacitor-based DVR, is proposed in [6] to improve LVRT capability of DFIG. The DVR with the improved control strategy and with the improved voltage sag detection system was connected to the generator export in series assisting DFIG to realize fault ride-through.

In this paper, a coordinated control strategy for DVR and crowbar circuits is proposed. Using MATLAB/Simulink, it is proved that this method can improve the transient voltage stability of the power network.

\section{System Structure and Working Principle}

The structure of the doubly-fed wind power integrated system based on the DVR and crowbar coordinated control is shown in Figure 1. Under normal condition, the DVR and crowbar are in the bypass, rotor side converter (RSC) and network side converter (GSC) guarantee the safety and stability of DFIG. When the grid faults occur, the improved DVR can dynamically compensate the voltage drop voltage. At the same time, the crowbar circuit can effectively limit the short circuit current in the rotor side. The coordinated control of the system can effectively improve the transient voltage stability of the system, so that DFIG can still achieve the grid operation. 


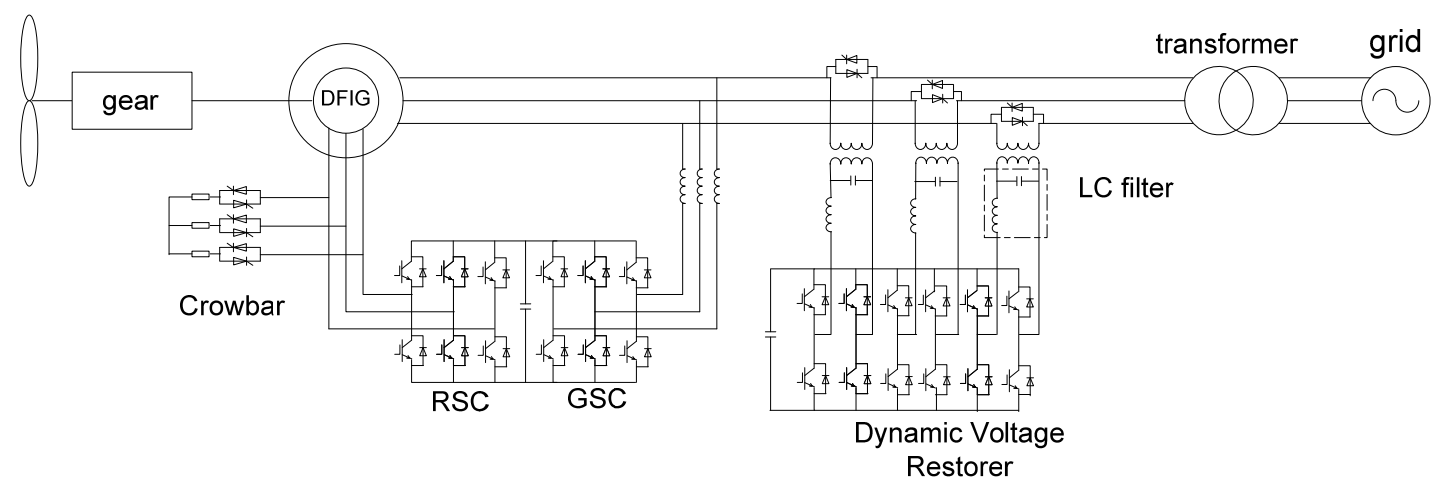

Fig.1 Structure of doubly-fed wind power integrated system based on DVR and crowbar

\section{DVR}

Usually, DVR can quickly detect the voltage fluctuation of the power network and effectively avoid the influence of the voltage instability on the system because the response time of DVR is in the millisecond level.

Improved voltage drop detection system of DVR

Control diagram of a single-phase software phase-locked loop based on LES filter is shown in Figure 2. Its working principle is described in [7].

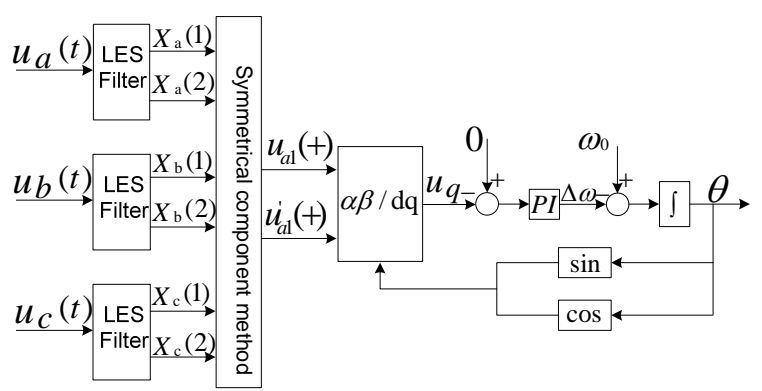

Fig.2 Software phase-locked loop

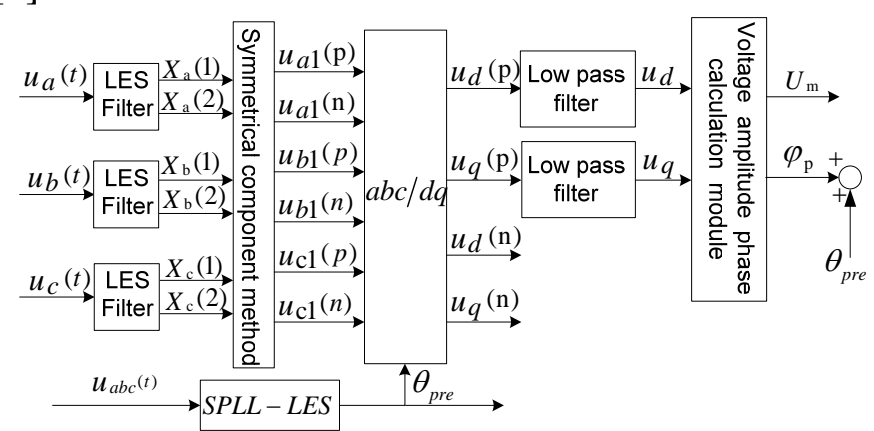

Fig.3 Voltage sag detection method of DVR

Voltage sag detection principle is shown in Figure 3. Positive sequence voltage amplitude $U_{m}$ in equation (1) and phase jump $\varphi_{p}$ in equation (2) can be obtained by the voltage amplitude and phase calculation module. By monitoring the changes of these two values, the voltage sag amplitude and phase jump can be judged.

$$
\begin{gathered}
U_{m}=\sqrt{u_{d p}{ }^{2}+u_{q p}{ }^{2}} \\
\varphi_{p}=\arctan \frac{u_{d p}}{u_{q p}}
\end{gathered}
$$

Figure 4 is the block diagram of DVR compensation. The ${ }^{d q}$ axis components $U_{d q p_{-} m}, U_{d q n_{-} m}$ of the fundamental positive and negative sequence components can be obtained after voltage sag detection. Four control circuits contain fuzzy PID regulator and control each phase respectively. The basic principle of the control circuit is that the voltage $\Delta U_{\text {ref }}$ of the DVR is obtained by comparing the difference between the voltage reference value and the actual value of the voltage given by detection system module, so that the voltage of the grid can be restored to the rated value. The fuzzy PID regulator is introduced to improve the dynamic response speed and compensation effect of DVR. 


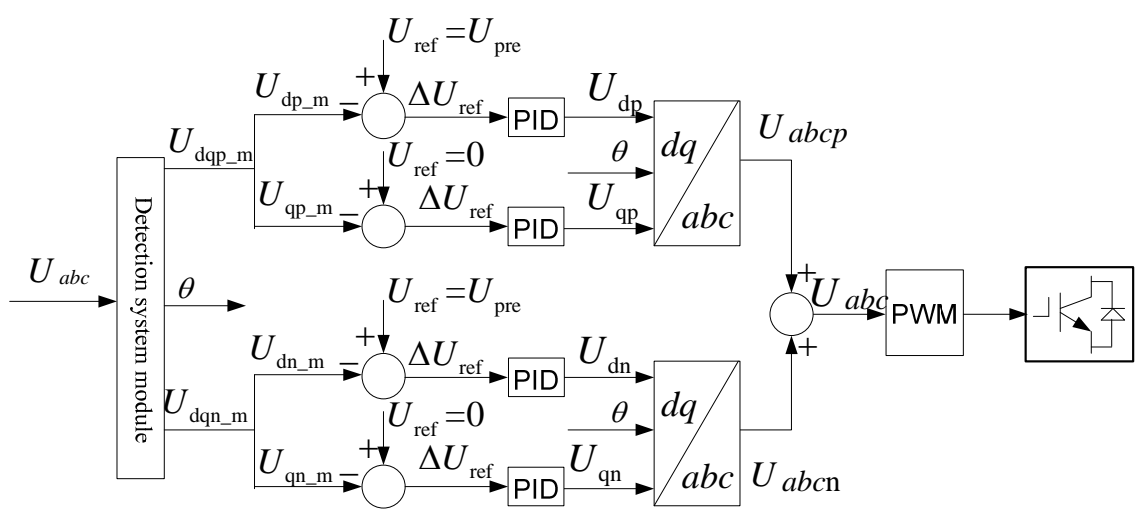

Fig.4 Compensation control strategy frame of DVR

\section{Crowbar Protection}

To protect the RSC from tripping due to over-currents in the rotor circuit or over-voltages in dc-link during grid faults, crowbar is installed in conventional DFIG wind turbines. The crowbar resistance and time that it quits are referenced in [3].

\section{Simulation Analysis}

To show the effectiveness of the proposed strategy, simulations have been performed using MATLAB/Simulink. The simulation results are shown in Figure 5 and Figure 6. Doubly-fed wind power integrated system consists of six DFIG whose capacity is $1.5 \mathrm{MW}$, the total capacity is $9 \mathrm{MW}$, the rated voltage of the stator is $575 \mathrm{~V}$, the stator resistance is $0.023 \mathrm{p} . \mathrm{u}$, the rotor resistance is $0.016 \mathrm{p} . \mathrm{u}$, the stator leakage inductance is 0.18p.u, the rotor leakage inductance is $0.16 \mathrm{p} . \mathrm{u}$. The grid voltage is $110 \mathrm{kV}$. Assuming that two types of short-circuit fault occurs:

(1) Three-phase symmetrical short circuit: three phase voltage drop to 0.33p.u. Simulation result is shown in Figure 5.

(2) Three-phase asymmetric short circuit: B phase voltage drops to 0.5p.u; C phase voltage drops to 0.67 p.u. Simulation result is shown in Figure 6.

The grid fault occurs in the $0.7 \mathrm{~s}$ to the $1.0 \mathrm{~s}$, the simulation time is set to $1.05 \mathrm{~s}$.

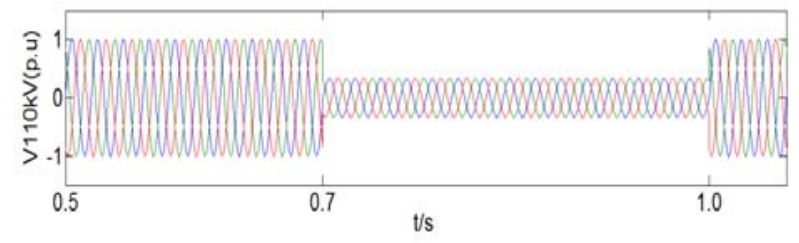

(a) Line voltage

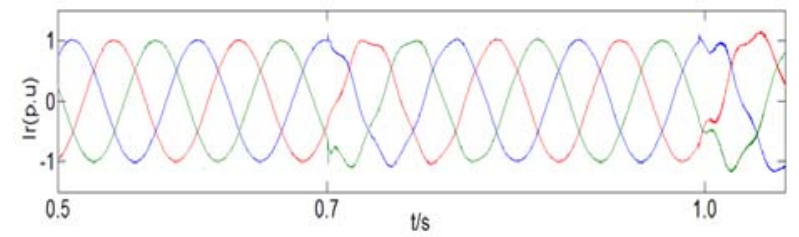

(c) Rotor current

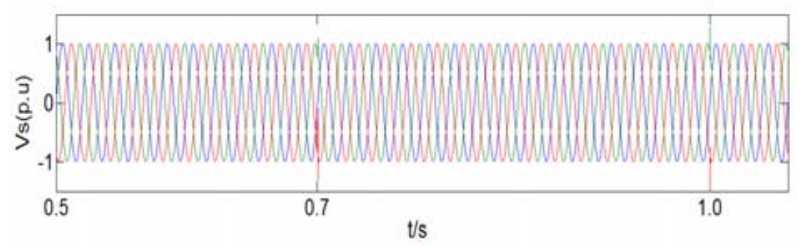

(b) Stator voltage

Fig.5 The simulation results of doubly-fed wind power integrated system under the three-phase symmetrical fault

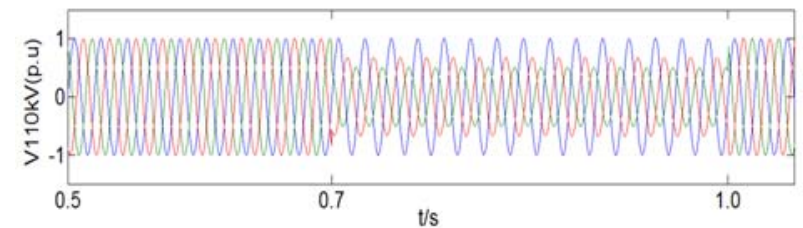

(a) Line voltage

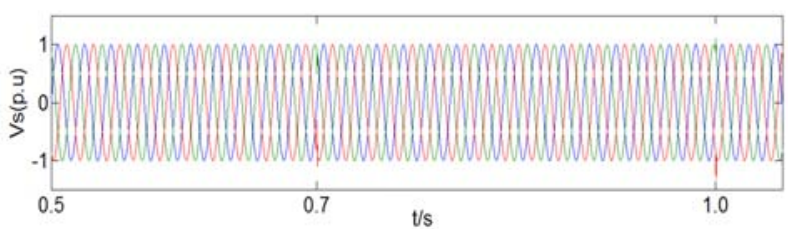

(b) Stator voltage 


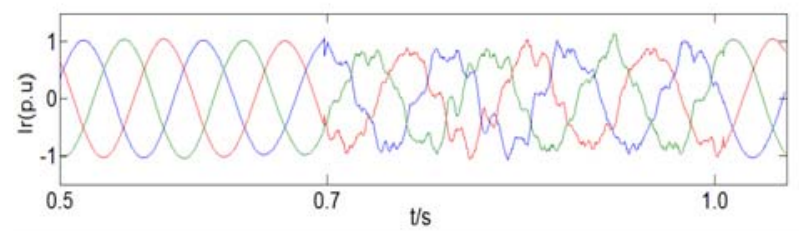

(c) Rotor current

Fig.6 The simulation results of doubly-fed wind power integrated system under the three-phase asymmetrical fault

From the pictures (b) in Figure 5and Figure 6, DVR can quickly compensate the three-phase voltage drop of the grid, so that the stator voltage can be quickly recovered, and the stator voltage is well supported. From the picture(c) in Figure 5and Figure 6, the crowbar circuit can be used to shunt the rotor side under the three-phase symmetrical and asymmetrical fault, so that a large instantaneous harmonic component does not appear in the rotor current. The rotor current can be recovered to normal operation in a period, and the damage to RSC of doubly-fed wind power generator is avoided.

\section{Conclusions}

(1) A new software phase locked loop and voltage sag detection algorithm based on LES filter and the modified symmetrical component method, which not only ensures the fast response of the detection algorithm, but also reduces the data fluctuation caused by the voltage distortion

(2) The DVR circuit is connected to the crowbar circuit, which can limit the current of the rotor side of the power grid, and protect the RSC from damage.

(3) Under the condition of symmetric and asymmetric short-circuit faults, the proposed coordinated control strategy can effectively improve the transient voltage stability of the system.

\section{References}

[1] S. Muller, M. Deicke, and R. De Doncker:IEEE Ind. Appl.Mag, Vol.8(2002),p. 26-33.

[2] J. Lopez, E. Gubia, P. Sanchis, X. Roboma, and L. Marroyo: IEEE Trans. Energy Convers, Vol 23(2008), p. 321-330.

[3] Xiaodong Zhu, Lei Shi, Ning Chen: Automation of Electrical Power Systems, Vol.18(2010) ,p. 84-89.In Cninese.

[4] WESSELS C,GEBHARDT F,FUCHS F W:IEEE Transactions on Power Electronics, Vol.26(2011),p.807-815.

[5] Jianbing $\mathrm{Xu}$, Quanyuan Jiang, Qingjun Shi: Automation of Electrical Power Systems, Vol.37(2013,p.14-20. In Cninese.

[6] Xiaoying Zhang, Zhizhuang Chen, Cunlu Dang:J.Huazhong Univ. of Sci. \& Tech,Vol.42(2014),p.35-39. In Cninese.

[7] Guodong Chen, Miao Zhu, Xu Cai: Proceeding of the CSEE, Vol.34(2014),p.4385-4394. In Cninese. 